\title{
Imaging long distance propagating calcium signals in intact plant leaves with the BRET-based GFP-aequorin reporter
}

\section{Tou Cheu Xiong ${ }^{1,2,3,4}$, Elsa Ronzier ${ }^{1,2,3,4}$, Frédéric Sanchez ${ }^{1,2,3,4}$, Claire Corratgé-Faillie ${ }^{1,2,3,4}$, Christian Mazars ${ }^{5,6}$ and Jean-Baptiste Thibaud ${ }^{1,2,3,4}$}

1 Biochimie et Physiologie Moléculaire des Plantes, Institut National de la Recherche Agronomique, UMR 386, Montpellier, France

2 Biochimie et Physiologie Moléculaire des Plantes, Centre National de la Recherche Scientifique, UMR 5004, Montpellier, France

${ }^{3}$ Biochimie et Physiologie Moléculaire des Plantes, SupAgro, Montpellier, France

${ }^{4}$ Biochimie et Physiologie Moléculaire des Plantes, UM2, Montpellier, France

${ }^{5}$ Laboratoire de Recherche en Sciences Végétales, Université de Toulouse, UPS, UMR 5546, Castanet-Tolosan, France

${ }^{6}$ Centre National de la Recherche Scientifique, UMR 5546, Castanet-Tolosan, France

\section{Edited by:}

Alex Costa, University of Milan, Italy

Reviewed by:

Zhi Qi, Inner Mongolia

University-Hohhot, China

Nathalie Leborgne-Castel, Université

de Bourgogne, France

Markus Schwarzländer, University of

Bonn, Germany

\section{*Correspondence:}

Tou Cheu Xiong, Biochimie et

Physiologie Moléculaire des Plantes,

Institut National de la Recherche

Agronomique, UMR 386/Centre

National de la Recherche

Scientifique, UMR 5004/Montpellier

SupAgro/Université Montpellier 2,

Campus INRA-SupAgro, Place Pierre

Viala, F34060 Montpellier Cedex 2,

France

e-mail: xiong@supagro.inra.fr
Calcium $\left(\mathrm{Ca}^{2+}\right)$ is a second messenger involved in many plant signaling processes. Biotic and abiotic stimuli induce $\mathrm{Ca}^{2+}$ signals within plant cells, which, when decoded, enable these cells to adapt in response to environmental stresses. Multiple examples of $\mathrm{Ca}^{2+}$ signals from plants containing the fluorescent yellow cameleon sensor (YC) have contributed to the definition of the $\mathrm{Ca}^{2+}$ signature in some cell types such as root hairs, pollen tubes and guard cells. $\mathrm{YC}$ is, however, of limited use in highly autofluorescent plant tissues, in particular mesophyll cells. Alternatively, the bioluminescent reporter aequorin enables $\mathrm{Ca}^{2+}$ imaging in the whole plant, including mesophyll cells, but this requires specific devices capable of detecting the low amounts of emitted light. Another type of $\mathrm{Ca}^{2+}$ sensor, referred to as GFP-aequorin (G5A), has been engineered as a chimeric protein, which combines the two photoactive proteins from the jellyfish Aequorea victoria, the green fluorescent protein (GFP) and the bioluminescent protein aequorin. The $\mathrm{Ca}^{2+}$-dependent light-emitting property of G5A is based on a bioluminescence resonance energy transfer (BRET) between aequorin and GFP. G5A has been used for over 10 years for enhanced in vivo detection of $\mathrm{Ca}^{2+}$ signals in animal tissues. Here, we apply G5A in Arabidopsis and show that G5A greatly improves the imaging of $\mathrm{Ca}^{2+}$ dynamics in intact plants. We describe a simple method to image $\mathrm{Ca}^{2+}$ signals in autofluorescent leaves of plants with a cooled charge-coupled device (cooled CCD) camera. We present data demonstrating how plants expressing the G5A probe can be powerful tools for imaging of $\mathrm{Ca}^{2+}$ signals. It is shown that $\mathrm{Ca}^{2+}$ signals propagating over long distances can be visualized in intact plant leaves and are visible mainly in the veins.

Keywords: Arabidopsis thaliana, calcium imaging, cooled CCD camera, GFP-aequorin, leaf, long distance calcium signaling, calcium waves, salt stress

\section{INTRODUCTION}

Calcium $\left(\mathrm{Ca}^{2+}\right)$ has long been established as a second messenger. Transgenic expression of fluorescence resonance energy transfer (FRET)-based fluorescent $\mathrm{Ca}^{2+}$ reporters such as the popular yellow cameleon (YC) or of the bioluminescent aequorin has permitted non-invasive monitoring of free $\mathrm{Ca}^{2+}$ levels and enabled real-time imaging of $\mathrm{Ca}^{2+}$ levels in different cell-types and organisms, including plants (Knight et al., 1991; Perez Koldenkova and Nagai, 2013). The YC has been used extensively for imaging $\mathrm{Ca}^{2+}$ signals in specific plant cell types such as guard cells (Allen et al., 1999), germinating pollen tubes (Iwano et al., 2012), and root hairs (Miwa et al., 2006; Monshausen et al., 2008). YC is also well suitable for $\mathrm{Ca}^{2+}$ sensing in subcellular compartments (Krebs et al., 2012; Bonza et al., 2013). However, YC requires excitation by exogenous light, which limits its relevance in plant photosynthetic tissues due to high background emission from auto-fluorescent cell walls, chlorophyll, and secondary metabolites. Indeed, wide autofluorescent spectrum of plant leaf pigments that overlap YC emission limits visualization of changes in intensity of YC fluorescence emission upon $\mathrm{Ca}^{2+}$ elevation. Moreover, $\mathrm{Ca}^{2+}$ imaging at plant tissue level requires strong and long excitation to detect fluorescence signals. Long term $\mathrm{Ca}^{2+}$ measurements would result in some YC photo-bleaching and/or tissue damage, this limiting long term $\mathrm{Ca}^{2+}$ measurements, over $24 \mathrm{~h}$ for example. On the other hand, the bioluminescent $\mathrm{Ca}^{2+}$ reporter aequorin does not require exogenous excitation light and very little background signal is produced resulting in a high signal-to-noise ratio throughout long acquisition periods. Aequorin has the largest dynamic range among $\mathrm{Ca}^{2+}$ reporters, allowing the monitoring of $\mathrm{Ca}^{2+}$ signals over several days and over a wide range of $\mathrm{Ca}^{2+}$ concentrations (Alonso and GarciaSancho, 2011). Aequorin has been introduced into several plant species (Knight et al., 1991; Webb et al., 2010) and has enabled photon counting based monitoring of $\mathrm{Ca}^{2+}$ in intact plant leaves. Many reports of aequorin application in plants have been published, where photon counting with luminometers was used to 
describe $\mathrm{Ca}^{2+}$ signaling under several stress conditions. However, to image photons emitted by aequorin with good resolution in both space and time requires sophisticated detection devices such as image photon detectors (IPDs) (Webb et al., 2010) or cameras fitted with an Intensified Charge-Coupled Device (ICCD) (Webb et al., 2010) or Electron Multiplying Charge-Coupled Device (EMCCD) (Rogers et al., 2008; Webb et al., 2010). This is a significant limitation to in planta $\mathrm{Ca}^{2+}$ imaging which could be overcome by using the G5A probe, an engineered fusion between the green fluorescent protein (GFP) and aequorin (Figures 1A,C) initially developed for $\mathrm{Ca}^{2+}$ imaging in animal cells (Baubet et al., 2000; Rogers et al., 2005). Through a bioluminescence resonance energy transfer (BRET) from aequorin to GFP, the wavelength of the emitted photon is $510 \mathrm{~nm}$, instead of $470 \mathrm{~nm}$ and detection yield by CCD is found optimized, compared to aequorin, with a better signal/noise ratio (Baubet et al., 2000; Rogers et al., 2005, 2008).

Here, (i) we applied G5A in Arabidopsis, (ii) we show that, in comparison to aequorin, G5A enhances in vitro and in vivo detection of weak $\mathrm{Ca}^{2+}$ events in intact plants, including in photosynthetic tissues and (iii) we describe a simple method that only

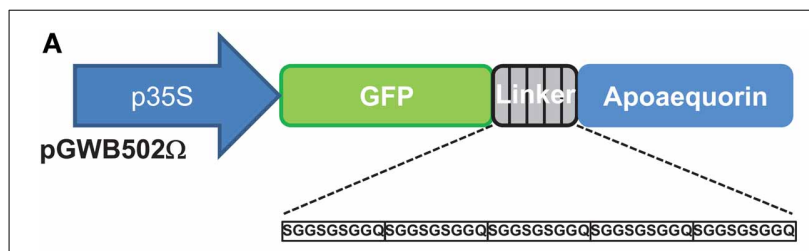

B
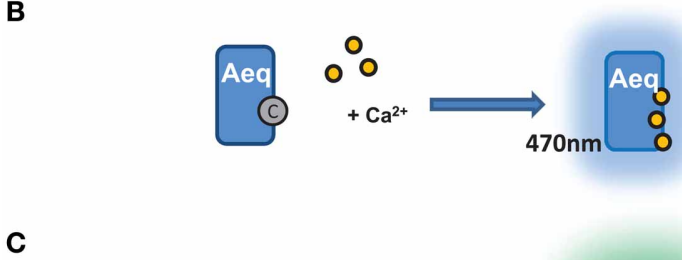

C
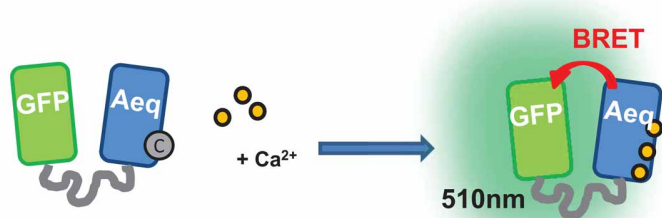

FIGURE 1 | Construction and operating principle of the G5A Ca ${ }^{2+}$ reporter. (A) Structure of the chimeric gene encoding the G5A sensor. The open-reading frame (ORF) encoding the green fluorescent protein (GFP) is linked to the ORF encoding the apo-aequorin by five repeats of a short sequence encoding a SGGSGSGGQ oligopeptide. The structure and length of this linker ensures efficient bioluminescence resonance energy transfer (BRET) between the aequorin and the GFP (Baubet et al., 2000). Using the pGWB502 $\Omega$ vector, constitutive G5A expression is driven by a $35 \mathrm{~S}$ promoter. (B) Principle of the aequorin bioluminescence emission upon binding of $\mathrm{Ca}^{2+}$. In the presence of the coelenterazine cofactor (" $\mathrm{C}$ "), the apo-aequorin is reconstituted as a functional aequorin. Upon binding of three $\mathrm{Ca}^{2+}$ ions, the cofactor is released with emission of light at $\sim 470 \mathrm{~nm}$. (C) Principle of G5A fluorescence emission upon binding of $\mathrm{Ca}^{2+}$. Thanks to the tight molecular coupling between the aequorin and GFP moieties of G5A, a BRET phenomenon between aequorin and GFP leads to excitation of and fluorescence emission at $510 \mathrm{~nm}$ by the latter. requires a cooled-CCD camera to visualize $\mathrm{Ca}^{2+}$ signals in plant leaves as, for example, $\mathrm{Ca}^{2+}$ waves propagating along leaf veins of intact plants after imposing a salt stress to roots of these plants. It is concluded that G5A reporter is an interesting alternative to aequorin.

\section{MATERIALS AND METHODS CLONING G5A AND ENGINEERING G5A-EXPRESSING PLANTS}

The original vector harboring the G5A construct (Baubet et al., 2000) was kindly provided by Dr. Philippe Brûlet's group (CNRS, Gif-sur-Yvette, France). The G5A coding sequence was cloned into the Gateway ${ }^{\circledR}$ entry vector $\mathrm{pDONR}^{\mathrm{TM}}$ by two sequential PCRs amplification using a G5A forward primer 5'-GGAGATAGAACCATGAGCAAGGGCGAGGAGCTGTTCA- $3^{\prime}$ and a $65 A$ reverse primer 5'-TCCACCTCCGGATCAGGGGAC AGCTCCACCGTAG- $3^{\prime}$, followed by a second PCR using a U5 forward primer 5'-GGGGACAAGTTTGTACAAAAA AGCAGGCTTCGAAGGAGAT-AGAACCATG-3' and a U3 reverse primer $5^{\prime}$-AGATTGGGGACCACTTTGTACAAGAAA GC-TGGGTCTCCACCTCCGGATC-3'. Next step was a transfer, by LR Gateway ${ }^{\circledR}$ recombination, of the G5A construct into the expression vector pGWB502 $\Omega$ (Nakagawa et al., 2007).

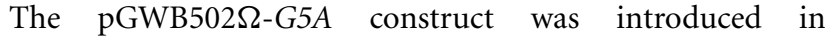
Agrobacterium tumefaciens (GV3101), for transformation of Arabidopsis thaliana ecotype Col-0 by the floral dip method (Clough and Bent, 1998). G5A expressing transgenic plants were selected using hygromycin selective media and checked for GFP fluorescence emission under direct excitation of GFP at $488 \mathrm{~nm}$ (see Figure 2). Homozygous G5A expressing T3 and T4 plants (here below denoted G5A plants) were used and compared to transgenic plants expressing aequorin in the cytoplasm (Col-0 ecotype, denoted below Aeq plants) obtained from Prof. Marc Knight (Durham, UK).

\section{PLANT MATERIAL AND GROWTH CONDITIONS}

Seeds from Aeq and G5A plants were surface-sterilized and placed on half-strength Murashige and Skoog plate medium supplemented with sucrose $1 \%(\mathrm{w} / \mathrm{v})$ and with hygromycin $(15 \mu \mathrm{g} / \mathrm{mL})(G 5 A)$ or kanamycin $(50 \mu \mathrm{g} / \mathrm{mL})(A e q)$, and stratified at $4^{\circ} \mathrm{C}$ for 2 days in the dark. Seedlings were subsequently grown in a growth chamber at $22^{\circ} \mathrm{C}$ with a $70 \%$ relative humidity, in long-day conditions $\left(150 \mu \mathrm{E} / \mathrm{m}^{2} / \mathrm{s}\right.$ light for $16 \mathrm{~h}$ a day) for 7 days. These 7-day old seedlings were either used directly or further grown in soil under short day conditions $\left(200 \mu \mathrm{E} / \mathrm{m}^{2} / \mathrm{s}\right.$ light for $8 \mathrm{~h}$ a day) for 3-7 weeks, as indicated.

\section{LUMINESCENCE MEASUREMENT AND IMAGING Seedlings}

In vivo reconstitution of functional aequorin was performed by incubating 7 day-old seedlings for $4 \mathrm{~h}$ at $22^{\circ} \mathrm{C}$ in the dark with a $2.5 \mu \mathrm{M}$ aqueous solution of coelenterazine HCP (Interchim). For imaging, coelenterazine-treated seedlings were placed within a dark chamber over a gelosed layer (water with $1 \%$ agar) in large Petri dishes. A cooled-CCD camera (Hamamatsu 4880-30), fitted at the top of the chamber, collected photons. Sequential image acquisition was carried out using the Hipic 5.1.0 software with an exposure time per image in the 15-60 s range (as indicated in the 


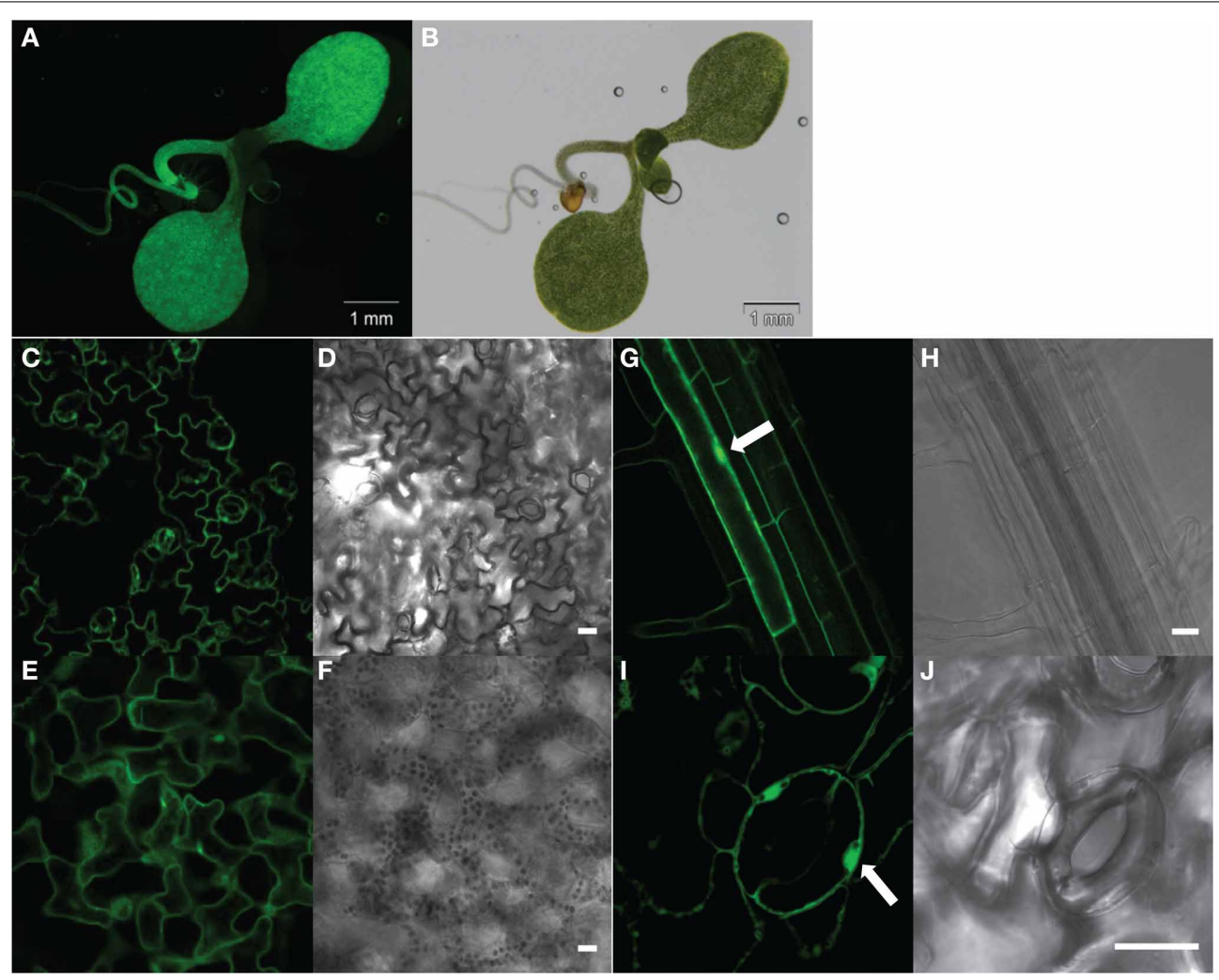

FIGURE 2 | Constitutive expression of the G5A fusion protein in all tissues of Arabidopsis thaliana seedlings. Seven (A-F) or 21 day-old (G-J) plants of the G5A line were checked for reporter expression by excitation of GFP (at $\lambda_{e x}=488 \mathrm{~nm}$ ) under a stereo microscope $(\mathbf{A}, \mathbf{B})$ or a confocal microscope (C-J). Fluorescence emission by GFP is shown in $(\mathbf{A}, \mathbf{C}, \mathbf{E}, \mathbf{G}, \mathbf{I})$ and corresponding bright field images are shown respectively in (B, D,F,H,J).
Fluorescent stereo microscope observation of intact seedlings allowed detection of GFP signals in cotyledons and the primary root $(\mathbf{A}, \mathbf{B})$. Confocal microscopy observation of leaf epidermal cells (C,D) and mesophyll cells (E,F) showed good expression of G5A in leaf tissues. G5A fluorescence was observed in both the cytosol and the nucleus (arrows) of root cells $(\mathbf{G}, \mathbf{H}$ ) and of stomatal guard cells $(\mathbf{I}, \mathbf{J})$. Scale bar $=20 \mu \mathrm{m}$.
Figure legends). Images were analyzed in ImageJ (Schneider et al., 2012). The first $5 \mathrm{~min}$ in each sequence were discarded because of chlorophyll autofluorescence decay.

\section{Older soil-grown plants}

At the end of the day, the soil was gently removed from the roots and the whole plants were incubated for $4 \mathrm{~h}$ at $22^{\circ} \mathrm{C}$ in the dark in a $2.5 \mu \mathrm{M}$ aqueous solution of coelenterazine HCP. Plants were then placed with the roots in Qualibact ${ }^{\circledR}$ (CEB) tubes filled with water through a hole in the cap of the tube to separate leaves from roots. Plants were left for $1 \mathrm{~h}$ in the dark at room temperature for recovery. Images of the rosette were acquired as described above for seedlings, with a 30 s integration time. $\mathrm{NaCl}$ at a final concentration of $200 \mathrm{mM}$ was injected with a remotely controlled syringe at the root level after 25 min of acquisition.

\section{Excised mature leaves}

Mature leaves were excised from 6-7-week old plants grown as described above and incubated at $22^{\circ} \mathrm{C}$ in the dark for $4 \mathrm{~h}$ in a $2.5 \mu \mathrm{M}$ aqueous solution of coelenterazine HCP. The treated excised leaf was then transferred to a dark chamber under the cooled-CCD camera for G5A imaging as described above with $15 \mathrm{~s}$ exposure time by frame. For salt stress, $100 \mu \mathrm{L}$ of $200 \mathrm{mM}$
$\mathrm{NaCl}$ was pipetted onto the excised leaf petiole (see Figure 8A arrow) and subsequent light emission was acquired.

\section{IMAGE ANALYSIS}

All images were analyzed in ImageJ. Shading correction of all images was performed by subtraction of a dark field image (acquisition without sample) acquired with the same exposure time. Backgrounds of each image were normalized by subtraction of ROIs of non-plant pixels. ROIs of plant pixels were then quantified and the average values are plotted over the time. Background noise after chlorophyll fluorescence decay was determined by imaging light emission from wild-type plant leaves and then subtracted for data obtained from $G 5 A$ or Aeq plants. $\mathrm{Ca}^{2+}$ signal velocity was determined with the MtrackJ plugin of ImageJ and the localization $(\mathrm{x}, \mathrm{y})$ of each velocity value was plotted with Matlab ${ }^{\circledR}$ software (R2006a).

\section{AEQUORIN IMMUNOBLOTTING}

Soluble protein was extracted from 50 pooled seedlings (Mithofer and Mazars, 2002) and separated by SDS-PAGE. Immunoblotting was carried out using an anti-aequorin rabbit polyclonal antibody (Novus Biological, NB100-1877) as described by the manufacturer. Signals of immunodetection were acquired with 
LAS-3000 imager (Fujifilm) and quantified with Multi-Gauge v3.2 (Fujifilm).

\section{CALIBRATION OF THE TWO PROBES G5A AND AEQUORIN}

Soluble proteins were extracted from G5A and Aeq plants as described by Mithofer and Mazars (2002) and were diluted in a buffer (Tris-HCl $200 \mathrm{mM}, \mathrm{pH} 7.4$, EGTA $5 \mathrm{mM}, \mathrm{NaCl} 0.5 \mathrm{M}$, $\beta$-mercaptoethanol $5 \mathrm{mM}$ ) containing the coelenterazine HCP cofactor for $2 \mathrm{~h}$ in the dark at $4^{\circ} \mathrm{C}$. Relative amounts of $\mathrm{G} 5 \mathrm{~A}$ and aequorin reporters in these crude extracts were estimated by immunoblotting (Figure 3A). So-called G5A and Aeq buffers were prepared by diluting soluble protein crude extracts from G5A and Aeq plants in Tris- $\mathrm{HCl} 200 \mathrm{mM}, \mathrm{pH}$ 7.0, EGTA $5 \mathrm{mM}$ at a protein content of $0.1 \mu \mathrm{g} / \mu \mathrm{L}$ and $0.15 \mu \mathrm{g} / \mu \mathrm{L}$ respectively (to ensure that subsequent in vitro comparison of both reporters was made with equal quantities of them). Wells of 96-well plates were filled with $50 \mu \mathrm{L}$ of different $\mathrm{Ca}^{2+}$ solutions, of which the free $\mathrm{Ca}^{2+}$ concentration was estimated by MaxChelator Software (http://www.stanford.edu/ cpatton/downloads.htm). To start probe calibration, $50 \mu \mathrm{L}$ of either G5A or Aeq buffer was dispensed into each well and maximum light emitted per second (L) was measured. In a second step, $100 \mu \mathrm{L}$ of a $2 \mathrm{M} \mathrm{CaCl}_{2}$ solution was dispensed into each well for discharging the remaining reconstituted $\mathrm{G} 5 \mathrm{~A}$ or aequorin reporters. Light emitted at this time $\left(\mathrm{L}_{\text {total }}\right)$ allowed the total amount of functional $\mathrm{Ca}^{2+}$ reporter to be estimated. All light measurements were made with a plate-spectrophotometer Victor ${ }^{2}$ (Perkin Elmer). Collected photons were integrated over $1 \mathrm{~s}$ lapses during $180 \mathrm{~s}$. Results are expressed as the ratio $\pm \mathrm{SE}$ of maximum light over total light $\left(\mathrm{L} / \mathrm{L}_{\text {total }}\right)$.

\section{RESULTS}

Effective transformation using the pGWB502 $\Omega-G 5 A$ construct was expected to yield a broad constitutive expression pattern of the G5A probe. This was checked in a $\mathrm{Ca}^{2+}$-independent manner by direct excitation, at $488 \mathrm{~nm}$, of the GFP moiety of the chimera probe (Figure 2).

A strong ubiquitous GFP signal was observed in 7 day-old seedlings. The subcellular pattern of the GFP signal suggested cytosolic and nuclear localization (arrows in Figures 2G,I).

An anti-aequorin polyclonal antibody (Novus Biological, USA) was used to evaluate the amount of G5A and aequorin proteins in the soluble protein fraction (Figure 3A). This antibody revealed strong bands at $22 \mathrm{kDa}$ and $52 \mathrm{kDa}$ in both protein extracts from Aeq and G5A plants. The G5A/aequorin ratio (protein level) was estimated at $1.48 \pm 0.14$.

Calibration curves were performed with soluble protein extracts from G5A or Aeq plants. Equal amounts of G5A and aequorin reporters were used for in vitro calibration curves. Data are expressed as maximum light emitted per second (denoted "L") (Fricker et al., 1999) over total light (denoted " $L_{\text {total }}$ ") ratio (Figure 3B see "Methods" section). G5A and aequorin showed similar responses to free $\mathrm{Ca}^{2+}$ concentration and calibration curves in Figure 3B do not differ significantly over the $10^{-8}$ to $10^{-6} \mathrm{M}$ free $\mathrm{Ca}^{2+}$ range. Linear regression between $10^{-8}$ to $10^{-6} \mathrm{M}$ free $\mathrm{Ca}^{2+}$ reveals a straight line with a slope of $1.065 \pm 0.016\left(R^{2}=0.988\right)$ and $0.888 \pm 0.015\left(R^{2}=0.987\right)$ for
A

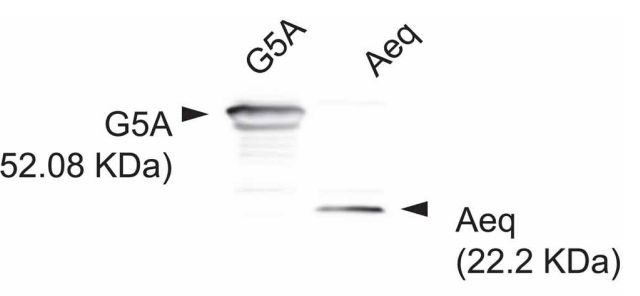

B

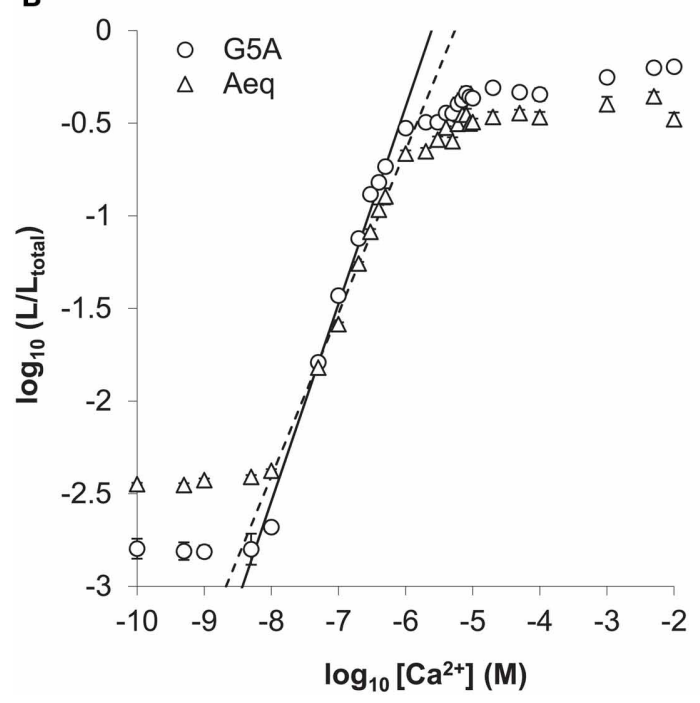

FIGURE 3 | In vitro calibration of G5A and aequorin as $\mathrm{Ca}^{2+}$ reporters. (A) Immunoblotting of soluble protein fractions from fifty 14 day-old plants of the G5A and Aeq lines with an anti-aequorin polyclonal antibody. Signals of immunoblotting were quantified and indicated as a G5A/aequorin ratio of protein accumulation of $1.48 \pm 0.14$ (average of one hundred seedlings obtained in two independent experiments $\pm \mathrm{SE}, n=2$ ). (B) In vitro calibration curves of G5A and aequorin in soluble protein extracts from G5A and Aeq plants. Equivalent amounts of $\mathrm{Ca}^{2+}$ reporters were used for the comparison (based on assay reported in $\mathbf{A}$ ) and incubated in a buffer containing $2.5 \mu \mathrm{M}$ coelenterazine HCP cofactor for $2 \mathrm{~h}$ in the dark at $4^{\circ} \mathrm{C}$ prior light emission assay in the presence of various free $\mathrm{Ca}^{2+}$ amounts (see Materials and Methods). Results are expressed as the ratio $\pm \mathrm{SE}$ ( $n=6$ in two independent experiments) of maximum light over total light $\left(L / L_{\text {total }}\right)$. The linear range of $L / L_{\text {total }}$ ratio as a function of free $\mathrm{Ca}^{2+}$ concentration is shown for G5A (full line) and aequorin (dashed line).

G5A and aequorin respectively (Figure $3 \mathbf{B}$ ). The reciprocal relationship, i.e., between free $\mathrm{Ca}^{2+}$ concentration and the rate of consumption of G5A or aequorin, can be represented by the equation:

$$
-\log \left(\left[C a^{2+}\right]\right)=a *-\log \left(\frac{L}{L_{\text {Total }}}\right)+b(\text { Fricker et al., 1999) }
$$

Coefficients $a$ and $b$ in the above equation are 0.93919 and 5.61289 for G5A, and 1.13646 and 5.26608 for aequorin.

The bioluminescent reporter aequorin has very low noise and high signal/noise ratio (Brini, 2008; Webb et al., 2010). No signal from G5A and aequorin was detected under in vitro conditions, in the absence of coelenterazine HCP. In the presence of coelenterazine $\mathrm{HCP}$ and without $\mathrm{Ca}^{2+}, \mathrm{G} 5 \mathrm{~A}$ and aequorin noise levels were respectively $271.16 \pm 10.76$ and $198.67 \pm 11.52$ RLU (Relative 
Light Unit). This difference is, however, negligible compared to signal after injection of free $\mathrm{Ca}^{2+}$. At the basal level of cytosolic free $\mathrm{Ca}^{2+}(0.1 \mu \mathrm{M})$, maximum light level was increased to $6.61 \times$ $10^{3} \pm 0.32 \times 10^{3}$ and $1.72 \times 10^{3} \pm 0.29 \times 10^{3} \mathrm{RLU}$ for G5A and aequorin respectively. At $1 \mu \mathrm{M}$ free $\mathrm{Ca}^{2+}$, light levels increased up to $90.14 \times 10^{3} \pm 7.44 \times 10^{3}$ and $20.25 \times 10^{3} \pm 1.65 \times 10^{3}$ RLU for G5A and aequorin respectively. Data expressed as signal/noise ratio for the two reporters (Figure 4A) show that G5A is approximately 3-5 times better than aequorin. For instance, the signal/noise ratio of aequorin with $1 \mu \mathrm{M}$ free $\mathrm{Ca}^{2+}$ is reached with only $300 \mathrm{nM}$ free $\mathrm{Ca}^{2+}$ with G5A reporter.

In parallel, comparison of the two $\mathrm{Ca}^{2+}$ reporters was performed in planta. Different time lapses were tested for collecting photons emitted by G5A and Aeq plants (Figure 4B). The threshold for signal detection for basal level of free $\mathrm{Ca}^{2+}$ was approximately $10 \mathrm{~s}$ and $30 \mathrm{~s}$ with G5A and aequorin respectively. A $30 \mathrm{~s}$ time lapse allowed sufficient light to be collected from $G 5 A$ plants while $1 \mathrm{~min}$ was hardly sufficient in the case of Aeq plants.

Sudden light-dark transition has been reported to induce weak $\mathrm{Ca}^{2+}$ signals in photosynthetic tissues (Johnson et al., 1995; Sai and Johnson, 2002; Dodd et al., 2006). To assess the capability of G5A to detect weak $\mathrm{Ca}^{2+}$ events in intact plant tissues, we challenged Arabidopsis plants with darkness: the reactions of G5A plants upon light-dark transition were compared to those of Aeq plants (Figure 5). Significantly more photons could be collected from $G 5 A$ plants than from the Aeq plants over this period (Figure 5B). Successive integrations of photons over $1 \mathrm{~min}$ time lapses provided an overview of the $\mathrm{Ca}^{2+}$ signal kinetics (Figure 5C). Dark-induced $\mathrm{Ca}^{2+}$ signals displayed by G5A and aequorin had parallel kinetics (Figure 5C and inset), with a maximal light emission between 40 and $60 \mathrm{~min}$. However, approximately five times more photons were detected from plants of the G5A line.

This interesting G5A feature allowed us to follow the dynamics of free $\mathrm{Ca}^{2+}$ in leaves triggered by a salt stress applied to roots of intact plants (Figure 6 and Supplementary videos S1, S2). The stress was sensed by roots and propagated to leaves, suggesting that $\mathrm{Ca}^{2+}$ waves might contribute to plant adaptation to salt stress. A time series of representative results (from video $\mathrm{S1}$ ) is presented in Figure 6A. It shows that a $30 \mathrm{~s}$ delay after the
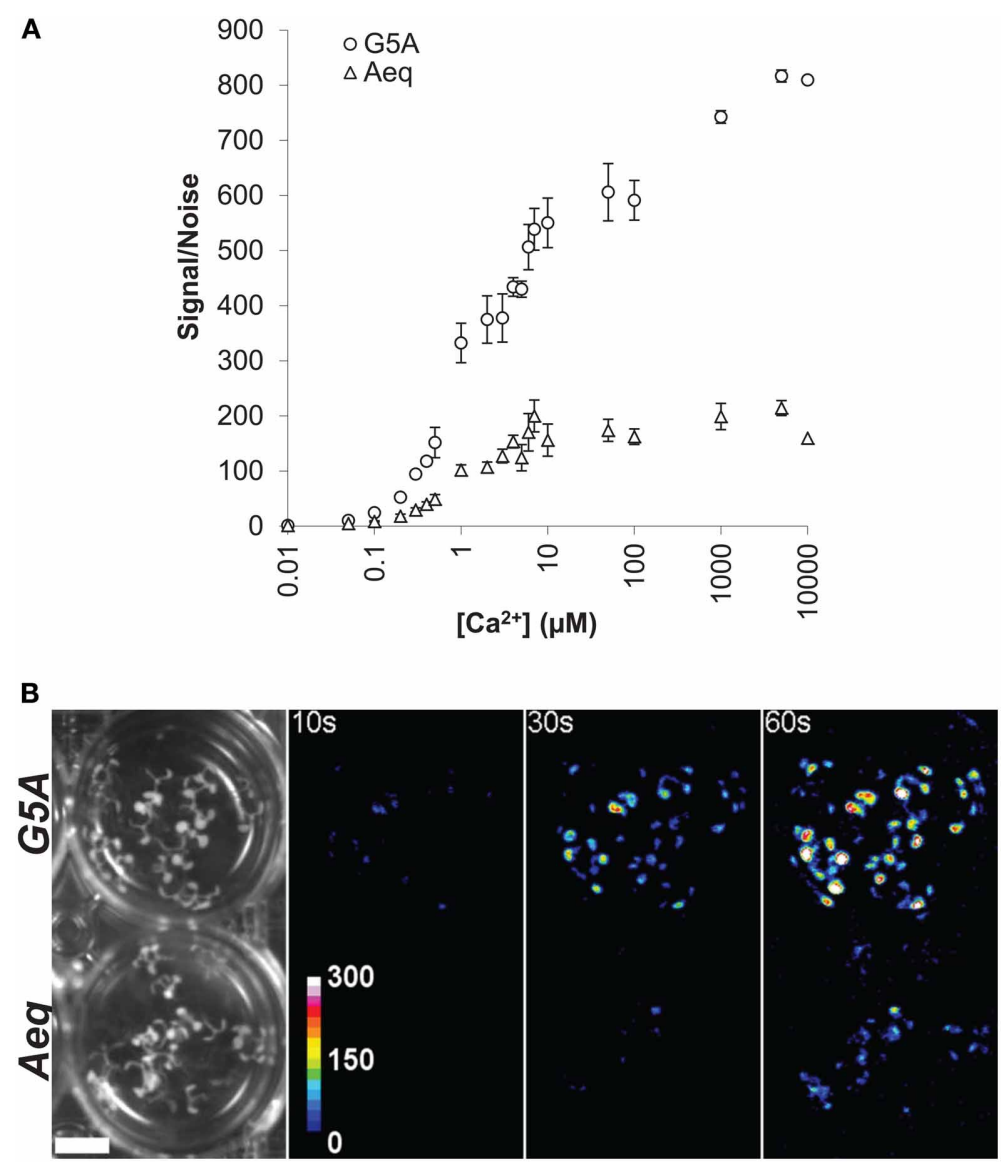

FIGURE 4 | In vitro and in vivo comparison of light emission by G5A and aequorin (A) In vitro assay of light emission from equal amounts of $\mathrm{Ca}^{2+}$ reporters G5A and aequorin is plotted against buffer free $\mathrm{Ca}^{2+}$ concentration. Results (mean $\pm \mathrm{SE}, n=6$ ) are expressed as the ratio of signal (maximum emitted light) over noise. (B) Representative in vivo
$\mathrm{Ca}^{2+}$ signals emitted from 7 day-old G5A (top) and Aeq (bottom) plants over different exposition time lapses $(10,30$, and $60 \mathrm{~s})$. Left panel shows bright field view (scale bar $=1 \mathrm{~cm}$ ) of the imaged plants. The other panels display cumulative $\mathrm{Ca}^{2+}$ responses in false colors (color scale in the $10 \mathrm{~s}$-labeled panel). 


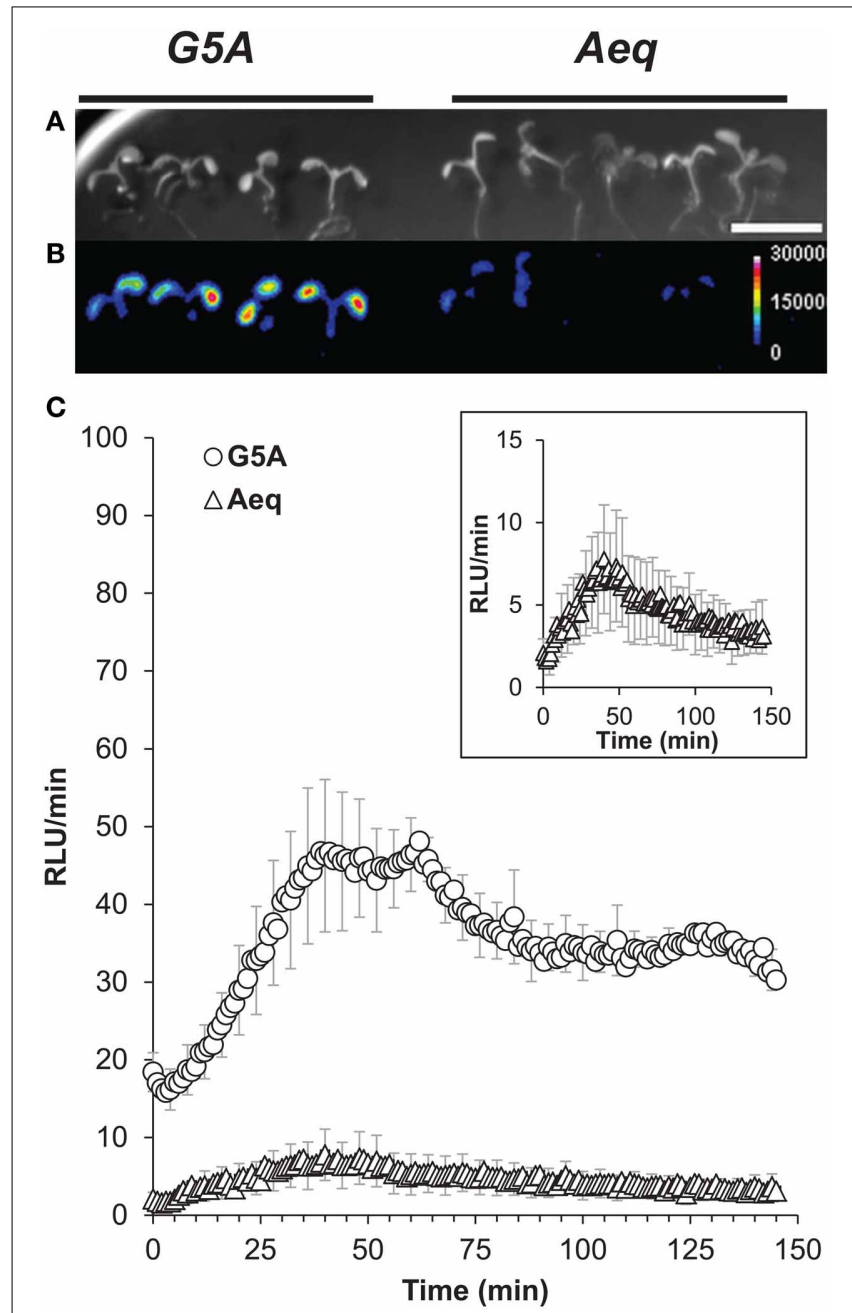

FIGURE 5 | $\mathrm{Ca}^{2+}$ dynamics detected in response to dark onset from plants expressing G5A or aequorin. (A) Bright field view of batches of 7 day-old G5A (left) and Aeq (right) Arabidopsis reporter lines. Scale bar = $1 \mathrm{~cm}$. (B) Cumulative amount of light emitted from these plants after dark onset, over $150 \mathrm{~min}$, expressed in false colors (scale shown at right, in device-dependent arbitrary unit or "RLU," standing for "relative light unit"). Representative results of 10 independent measurements of dark-induced $\mathrm{Ca}^{2+}$ released. (C) 150 min time course of the cumulative light emission over $60 \mathrm{~s}$ time lapses from plants in $(\mathbf{A}, \mathbf{B})$ (data are means \pm SE of 10 independent experiments with four G5A and five Aeq plants). $\mathrm{Ca}^{2+}$ dynamics from the Aeq plants show kinetics (inset) similar to G5A plants but with approximately five times less light emission.

application of $\mathrm{NaCl}$ (at time $=0$ ) was required before $\mathrm{Ca}^{2+}$ levels increased in the petioles. Elevated calcium levels then propagated to the rest of the leaves. It is interesting to note that the $\mathrm{Ca}^{2+}$ responses of mature and young leaves differed in terms of kinetics. Mature leaves responded by an initial rapid, transient, $\mathrm{Ca}^{2+}$ peak (Figure 6A, time $=1-2 \mathrm{~min}$ ) followed by a second very slow, wave-like, increase and subsequent decrease of free $\mathrm{Ca}^{2+}$ level lasting more than $50 \mathrm{~min}$ (from 6 to $60 \mathrm{~min}$ ) with a maximum at $12-13 \mathrm{~min}$. The young leaves displayed a single rapid $\mathrm{Ca}^{2+}$ transient peak (Figure 6A red arrows), similar to that observed in mature leaves although slightly later $(3.5-4.5 \mathrm{~min}$ after salt stress application). Defining the whole plant as an ROI and plotting the time course of the signal summed over each $30 \mathrm{~s}$ lapse (in RLU/30 s) for $60 \mathrm{~min}$ after salt stress application yielded a dynamic view of these $\mathrm{Ca}^{2+}$ events at leaf level (Figure 6B). It was found that both the $\mathrm{Ca}^{2+}$ peaks (observed for mature and young leaves) and the $\mathrm{Ca}^{2+}$ wave had a maximum at 19-20 RLU/30 s (Figure 6B). Despite inevitable variations from a plant to another one, an analogous pattern of distribution in space and time of $\mathrm{Ca}^{2+}$ events was observed when challenging a plant with a salt stress at the root level (Supplementary video S2).

Light emitted by G5A in intact plants facing a salt stress therefore appeared to be sufficiently intense to image the propagation of $\mathrm{Ca}^{2+}$ signals in leaves with good time resolution. We performed a simple analysis of $\mathrm{Ca}^{2+}$ waves on each leaf of plants subjected to a salt stress applied to roots. $\mathrm{Ca}^{2+}$ signal velocities were then calculated for each leaf of the plant shown in Figure 6 (red dashed arrows, Figure 7). This shows that velocity was not constant within a given leaf (it decreased at leaf tip) and differed depending on the leaf. Detailed numerical values are given (Table 1): maximum and minimum of velocities were 0.52 and $0.03 \mathrm{~mm} / \mathrm{s}$ respectively.

Further applications of G5A were investigated by imposing similar salt stress on mature leaves excised from 7-8 week-old plants (Figure 8). Application of $100 \mu \mathrm{L}$ of $200 \mathrm{mM} \mathrm{NaCl}$ onto the petiole end of an excised leaf (Figure 8A, white arrow) was enough to generate detectable elevations in free calcium after $1 \mathrm{~min}$. They started immediately after the exposure to the $\mathrm{NaCl}$ solution at the site of application before they spread throughout the rest of the leaf (Figure 8A and Supplementary videos S3, S4). The propagation of free calcium elevation seems to be different in the basal third part of the leaf (denoted by $*$ in Figure 8C) as compared to the rest of the leaf (denoted by $* *$ in Figure $8 \mathrm{C}$ ). In the early phase of response to the applied stress, increase in free $\mathrm{Ca}^{2+}$ were observed in the peripheral regions of the basal third part of the leaf and not in the middle vein. Subsequently, $\mathrm{Ca}^{2+}$ responses seem to propagate throughout the leaf, firstly, along the vascular tissues (primary and secondary veins) and later in the mesophyll tissue. Quantification of increase in free $\mathrm{Ca}^{2+}$ from the entire leaf shows that salt stress induced two different peaks of $\mathrm{Ca}^{2+}$, which correspond to these two successive episodes of $\mathrm{Ca}^{2+}$ increase, firstly in the basal part of the leaf, subsequently in the rest of the leaf (as indicated by asterisks in Figure $\mathbf{8 B}$ as described for Figure 8C).

In this example (representative of five independent leaves), elevation of free $\mathrm{Ca}^{2+}$ induced by $\mathrm{NaCl}$ needed $315 \mathrm{~s}$ (image at 1:00 to $6: 15)$ to travel through a $57 \mathrm{~mm}$-long leaf. Thus, in this example the average velocity was $0.181 \mathrm{~mm} / \mathrm{s}$. A further analysis was performed on the primary vein of this leaf (Figure 8C, red dashed line $\mathrm{X}-\mathrm{Y}$ ), a kymographic representation of velocity value on the axis $\mathrm{X}-\mathrm{Y}$ shows that there were three different $\mathrm{Ca}^{2+}$ response velocities (Figure 8D). Two of them (red dashed and orange dashed arrows) spread acropetally (from X to $\mathrm{Y}$ ) whereas one propagated the opposite way ( $\mathrm{Y}-\mathrm{X}$, cyan dashed arrow). Interestingly, between the first third and the second third of the leaf, was observed a region where no $\mathrm{Ca}^{2+}$ signals were detected with G5A. Despite this gap, $\mathrm{Ca}^{2+}$ signal propagation was observed all along the XY axis (Figure 8C and Supplementary video S3). 

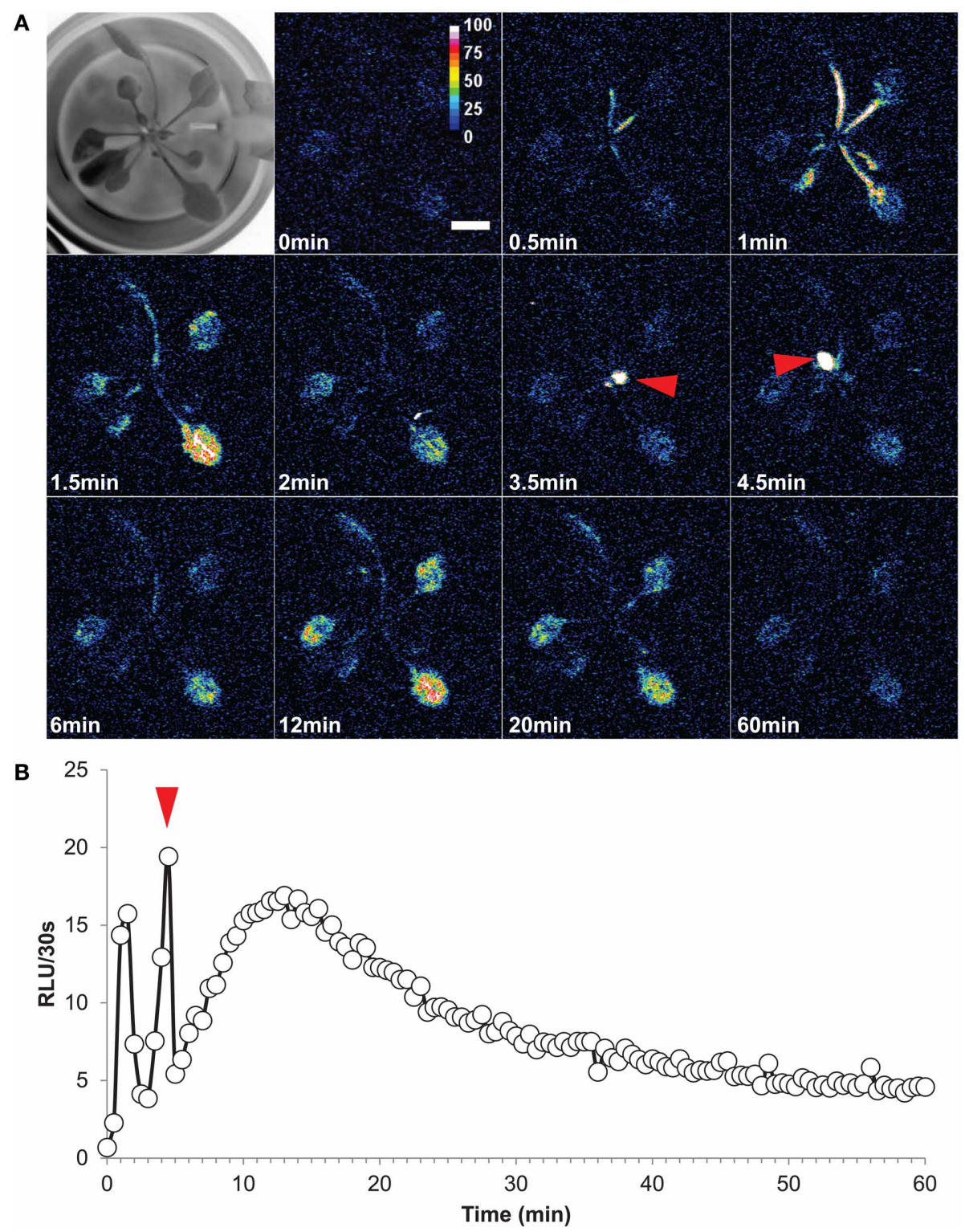

FIGURE 6 | High salt exposition of roots elicits long distance $\mathrm{Ca}^{2+}$ dynamics in leaves. (A) Time series of images (time of capture indicated in the left bottom corner of each image) showing propagation of $\mathrm{Ca}^{2+}$ elevation in aerial part of an intact plant (Representative result of five independent plants). First image of the series is a bright-field view of the plant. At time $=0$, a solution of $\mathrm{NaCl}(200 \mathrm{mM}$ final concentration) was applied to roots and light subsequently emitted from leaves was accumulated over 60 min (each image shows cumulative light intensity over a $30 \mathrm{~s}$ time lapse). After $0.5 \mathrm{~min}, \mathrm{Ca}^{2+}$ elevations were detected on petioles and propagation of $\mathrm{Ca}^{2+}$ responses to the end of each mature leaf were observed. Young leaves responded only at 3.5-4.5 min after $\mathrm{NaCl}$ stress (red arrows) (B) Quantification of light signals from the whole plant over $60 \mathrm{~min}$. As in (A) the red arrow indicates the short $\mathrm{Ca}^{2+}$ response in young leaves.
Analyses of $\mathrm{Ca}^{2+}$ waves on this excised leaf (representative of five leaves) show that $\mathrm{Ca}^{2+}$ signal velocities along different veins (Figure 9A dashed arrows) were different. Local velocity values were plotted on the image (as spots in false-color scale, Figure 9B). Higher velocities in the center of the leaf and slower velocities at leaf borders were found (Figure 9B). Details of velocities of $\mathrm{Ca}^{2+}$ signals in leaf veins, including on $\mathrm{X}-\mathrm{Y}$ axis $(\# 1, \# 8$, and \#16) are presented in Table 2 below. Despite inevitable variation from a leaf excised from a plant to another leaf excised from another plant, the nature and pattern (both in space and time) was essentially reproducible (see Supplemental video S4).

\section{DISCUSSION}

Since the successful use of aequorin as a $\mathrm{Ca}^{2+}$-signaling reporter in plant tissues (Knight et al., 1991), examples of aequorin imaging in plants have relied on the use of ultra-sensitive camera devices (intensified-CCD or electron-multiplying-CCD) to detect the few photons emitted by aequorin. They have revealed, for 
example, that $\mathrm{Ca}^{2+}$ oscillations occur during diurnal rhythms in plant leaves (Johnson et al., 1995; Sai and Johnson, 2002; Dodd et al., 2006). Optimized imaging of aequorin signals in plants has been reported recently that, with integration time

A

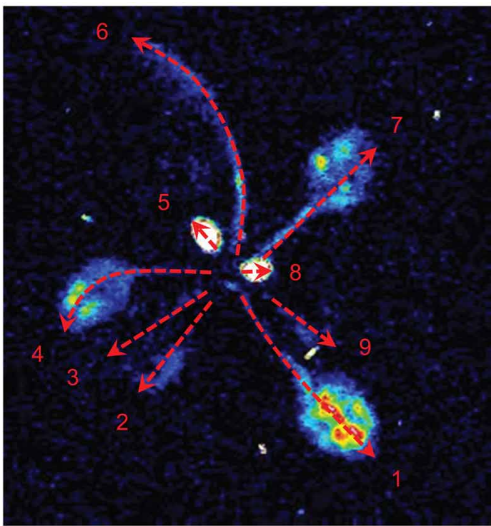

B

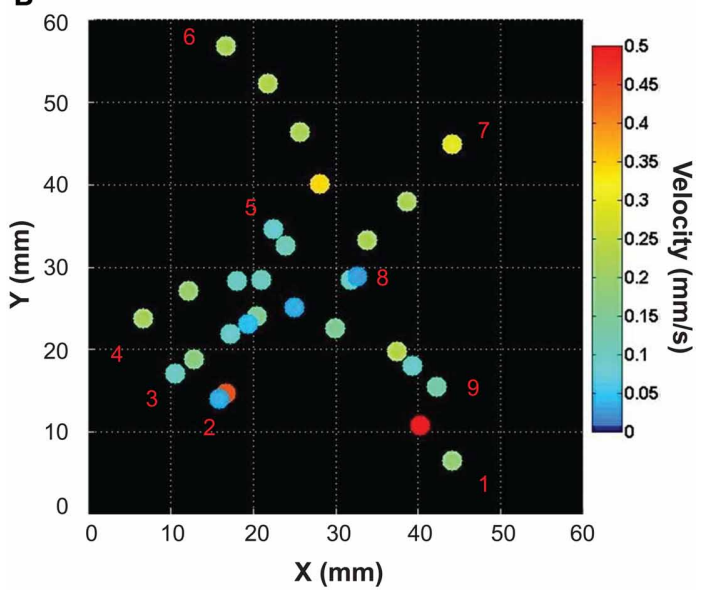

FIGURE 7 | Analysis of the propagation of $\mathrm{Ca}^{2+}$ elevations induced by high salt stimulus applied to roots. (A) Free $\mathrm{Ca}^{2+}$ elevations on each leaf were analyzed with Image J. Velocities $(\mathrm{mm} / \mathrm{s})$ of $\mathrm{Ca}^{2+}$ responses were determined for each leaf along paths figured by red dashed arrows (values of $\mathrm{Ca}^{2+}$ response velocity are presented on Table 1). (B) Propagation speeds along the main leaf vain are indicated for selected points (same space scale as in A). False color scale is in $\mathrm{mm} / \mathrm{s}$. down to $40 \mathrm{~s}$, showed stimulus- and tissue-specific $\mathrm{Ca}^{2+}$ signatures in seedlings (Zhu et al., 2013). In these examples of aequorin imaging in plants, however, low light detection relied upon sophisticated and costly equipment. Another interesting development of aequorin-based approach to in planta $\mathrm{Ca}^{2+}$ signaling has recently been reported: expression of aequorin in specific cell types of Arabidopsis was used to determine which cell types release calcium into the cytosol in response to a given stimulus (Marti et al., 2013). Photometry (with high time resolution) of aequorin emission from plants expressing the $\mathrm{Ca}^{2+}$-sensor in specific leaf cell-types (mesophyll cells, guard cells, [peri-]vascular cells, epidermal cells, and trichomes) may be used to follow various stresses. These experimental conditions allowed the collected information to be ascribed to a given cell-type, without spatial localization of the measured signals.

The G5A-based method we report here provides an interesting complement to these recent improvements of aequorin-based methods. In the Aequoria victoria jellyfish, a naturally evolved BRET phenomenon between aequorin and GFP occurs. Several artificial proteins assembling aequorin with GFP-derived proteins have been engineered to mimic the natural BRET observed in Aequoria victoria. Performance of these artificial $\mathrm{Ca}^{2+}$ reporters depends on the linker motif placed in between the BRET partner proteins (Baubet et al., 2000; Gorokhovatsky et al., 2004). Comparison of different linkers in GFP-aequorin protein fusions has demonstrated that the five repeat motifs used here in the so-called G5A artificial reporter (see Figure 1) allows a high BRET efficiency (Baubet et al., 2000). Subsequently, the G5A reporter has been successfully used to monitor $\mathrm{Ca}^{2+}$ elevation at cellular and organ levels in animals (Baubet et al., 2000; Chiesa et al., 2001; Cassidy and Radda, 2005; Rogers et al., 2005, 2008; Martin et al., 2007; Naumann et al., 2010). To date, however, no G5A application in plants has been reported.

Although our in vitro assays show similar calibration curves for both reporters (Figure 3B), there was a significantly better signal/noise ratio for G5A than for aequorin (Figure 4A) corresponding to a 3-5 fold increase in light collected from the former compared to the latter. Such an amplification is consistent with the data obtained in planta (Figures $4 \mathbf{B}, \mathbf{5}$ ) where small changes of free $\mathrm{Ca}^{2+}$ concentration were more easily detected with G5A than with aequorin. The (up to) 5-fold amplification of light in plants expressing G5A is similar to the 5.7-fold increase

Table 1 / $\mathrm{Ca}^{2+}$ wave properties in different leaves of an intact plant.

\begin{tabular}{|c|c|c|c|c|c|c|}
\hline $\begin{array}{l}\text { Leaf } \\
\text { number }\end{array}$ & $\begin{array}{c}\text { Total length } \\
\text { (mm) }\end{array}$ & $\begin{array}{l}\text { Velocity mean } \\
(\mathrm{mm} / \mathrm{s})\end{array}$ & $\begin{array}{l}\text { Velocity minimum } \\
\qquad(\mathrm{mm} / \mathrm{s})\end{array}$ & $\begin{array}{l}\text { Velocity maximum } \\
\qquad(\mathrm{mm} / \mathrm{s})\end{array}$ & $\begin{array}{l}\text { Duration* } \\
\text { (s) }\end{array}$ & $\begin{array}{l}\text { Latency* } \\
\text { (s) }\end{array}$ \\
\hline 1 & 25.96 & $0.29 \pm 0.10$ & 0.15 & 0.52 & 90 & 30 \\
\hline 3 & 16.87 & $0.11 \pm 0.02$ & 0.05 & 0.18 & 150 & 60 \\
\hline 4 & 18.50 & $0.15 \pm 0.03$ & 0.10 & 0.23 & 120 & 30 \\
\hline 5 & 5.84 & $0.10 \pm 0.01$ & 0.08 & 0.11 & 60 & 240 \\
\hline 7 & 22.19 & $0.25 \pm 0.02$ & 0.22 & 0.30 & 90 & 30 \\
\hline 8 & 3.68 & $0.06 \pm 0.03$ & 0.03 & 0.09 & 60 & 210 \\
\hline 9 & 13.67 & $0.15 \pm 0.04$ & 0.09 & 0.24 & 90 & 90 \\
\hline
\end{tabular}

*Time resolution is limited by the time acquisition (30 s). 
A
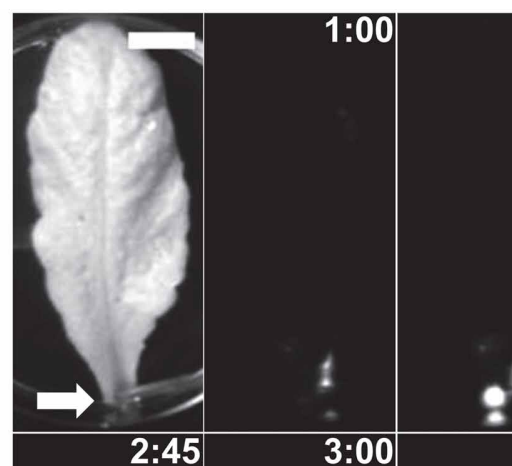

3:00

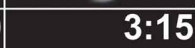

$1: 15$

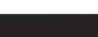

$1: 3$

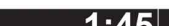

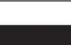

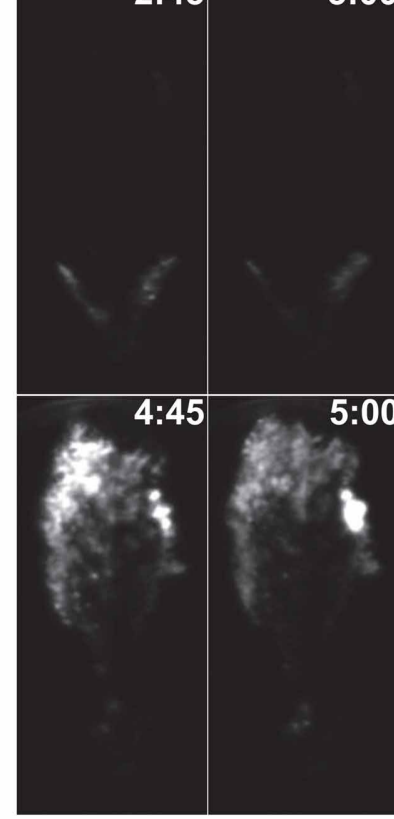

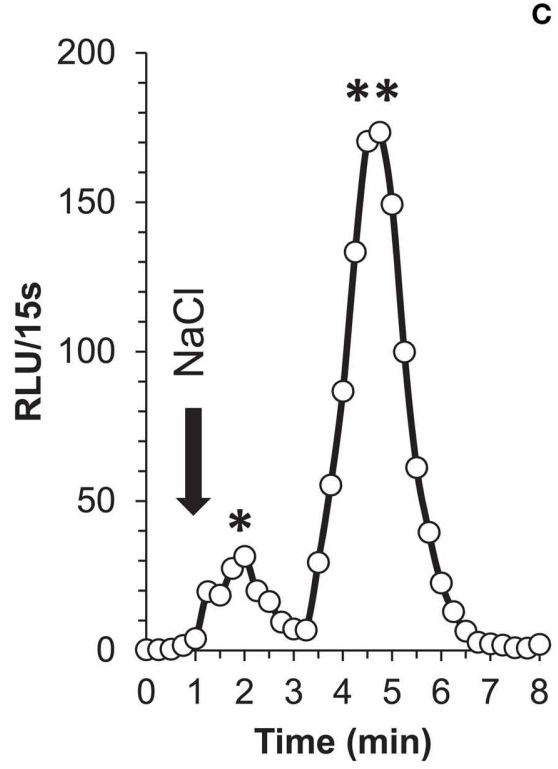

C

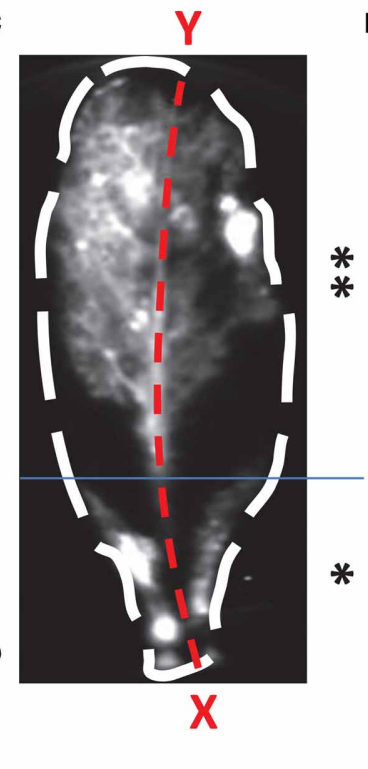

D

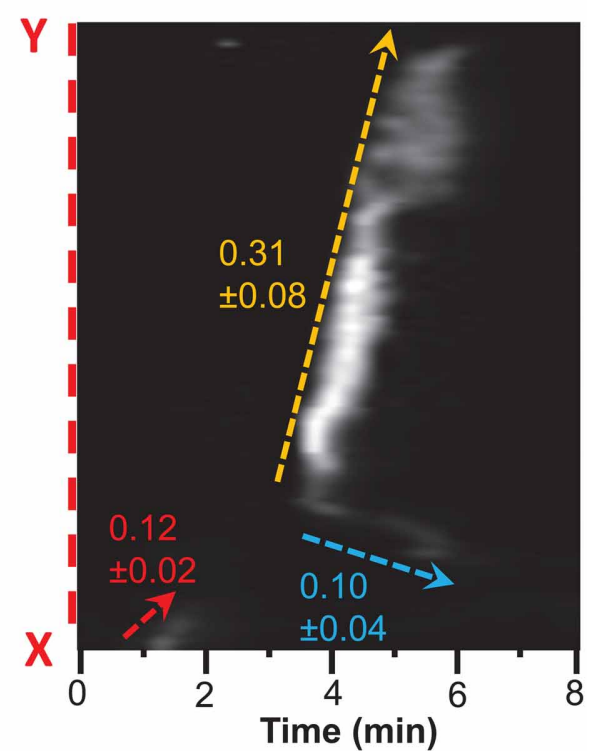

FIGURE 8 | Salt application on detached leaf elicits $\mathrm{Ca}^{2+}$ waves along the vascular tissue. (A) Time series of images (time of capture indicated in the right top corner of each image in min:s) showing propagation of $\mathrm{Ca}^{2+}$ responses in a detached leaf. First image of the series is a bright-field view of the plant. At time $=1 \mathrm{~min}, 100 \mu \mathrm{L}$ of a solution of $\mathrm{NaCl}(200 \mathrm{mM})$ was dispensed onto the petiole (white arrow) and light subsequently emitted from leaves was integrated over $7 \mathrm{~min}$ (each image shows cumulative light over (Continued) 


\section{FIGURE 8 | Continued}

a $15 \mathrm{~s}$ time lapse). $\mathrm{Ca}^{2+}$ responses were immediately detected on petioles and propagation of $\mathrm{Ca}^{2+}$ responses to the end of leaf was observed. Scale bar $=1 \mathrm{~cm}$. Calibration bar in gray scale is shown in the last image (RLU). Representative result of five independent experiments. (B) Quantification of light signals from ROI for the whole leaf (see C) over 8 min (in RLU per $15 \mathrm{~s}$ ). At time $=1 \mathrm{~min}, \mathrm{NaCl}$ was applied onto the petiole (black arrow).

The two peaks denoted by $*$ and $* *$ correspond to a $\mathrm{Ca}^{2+}$ increase in the basal third and the rest of the leaf respectively. (C) Localization of $\mathrm{Ca}^{2+}$ responses is represented by a z-stack of standard deviation of $\mathrm{Ca}^{2+}$ signals over the $8 \mathrm{~min}$ of measurement. $\mathrm{Ca}^{2+}$ signals seem to take place in leaf veins. The basal third of the leaf is indicated by $*$ and the rest of the leaf by $* *$. Line scan of primary vein (red dashed line $\mathrm{X}-\mathrm{Y}$ ) is analyzed in (D). (D) Kymographic representation of $\mathrm{Ca}^{2+}$ signals in the primary vein (X-Y from C). Three different velocities of $\mathrm{Ca}^{2+}$ signals could be measured and are indicated. in the light signal resulting from BRET between luciferin and GFP in Renilla reniformis (Ward and Cormier, 1976). It is interesting to note however that the improved detection of light emission from aequorin through BRET is still not completely understood (Webb et al., 2010). In the jellyfish Aequorea victoria, aequorin is associated with the GFP that allows the amplification of light by BRET phenomena. In vitro, the binding between aequorin and GFP does not occur, even at high concentration and no BRET events was observed (Baubet et al., 2000). Fusion of aequorin and GFP is a prerequisite to observe such natural light amplification seen in jellyfish. Baubet et al. have designed an optimized linker that results in sufficient high quantum yield to visualize $\mathrm{Ca}^{2+}$ induced light emission from G5A (Baubet et al., 2000).

An issue for plant cell physiologists is the autofluorescence of chlorophyll and other organic pigments which hinders the use of fluorescent probes with overlapping spectroscopic properties. For instance chlorophyll $b$ and carotenoids (lutein, neoxanthin, and violaxanthin) have major absorption peaks between 469 and $490 \mathrm{~nm}$ (Rivadossi et al., 2004; Taylor et al., 2006) and may absorb photons emitted at $\sim 470 \mathrm{~nm}$ by aequorin in leaf cells. As a consequence of the efficient BRET between its aequorin and GFP moieties, G5A emits photons at $510 \mathrm{~nm}$ (Baubet et al., 2000; Rogers et al., 2005, 2008), thus reducing absorbance by plant tissues and resulting in better detection by cameras or luminometers. This also could contribute to the better performance of G5A compared to aequorin in the present in planta experiments (Figure 5C).

In addition to these considerations, the G5A-based results that we report here exemplify the possibilities that this $\mathrm{Ca}^{2+}$ reporter holds for plant biologists. Comparison of Aeq and G5A plants subjected to darkness shows that similar responses could be visualized with both $\mathrm{Ca}^{2+}$ reporters, but five times more light was emitted from $G 5 A$ plants (Figure 5). This suggests that $\mathrm{G} 5 \mathrm{~A}$ is an alternative tool to aequorin for $\mathrm{Ca}^{2+}$ imaging when signals are either too low or if ultra-sensitive camera is not available. Moreover, further examples of potential application of G5A are introduced here, showing the analysis of longdistance $\mathrm{Ca}^{2+}$ signaling (potentially involved in the coordination of the integrative responses of plant to stresses, here salt stress, Figures 6-9).

Long distance propagation of $\mathrm{Ca}^{2+}$ signals (" $\mathrm{Ca}^{2+}$ waves") is attracting increasing interest in the plant biology community (Steinhorst and Kudla, 2013) and in this context, G5A seems to be a complementary tool, along with fluorescent $\mathrm{Ca}^{2+}$ reporters, to investigate complex cell to cell communication within plants. Most of $\mathrm{Ca}^{2+}$ imaging experiments in intact tissue with a fluorescent reporter have been carried out in roots (Fasano et al., 2001; Monshausen et al., 2011; Gjetting et al., 2012), where auto-fluorescence is much less of an obstacle than in leaves. It is by using FRET-confocal laser scanning microscopy that $\mathrm{Ca}^{2+}$ imaging on leaves with YC has recently been reported (Benikhlef et al., 2013; Verrillo et al., 2014). Aequorin imaging requires ultrasensitive cameras (intensified-CCD or electron-multiplied-CCD) while G5A imaging does not. The high dynamics and intensity of G5A light emission upon $\mathrm{Ca}^{2+}$ events open opportunities to detect low $\mathrm{Ca}^{2+}$ signals and to analyse their propagation with good time resolution, using a "regular" cooled CCD camera. In practical terms, time resolution is the time required to make an image (a frame) with an acceptably high signal/noise ratio. Under the present experimental conditions, integration time for a frame was well under $1 \mathrm{~min}$ : depending on amplitude of the $\mathrm{Ca}^{2+}$ signal this integration time ranged from $30 \mathrm{~s}$ (Figure 6) down to $15 \mathrm{~s}$ (Figure 8) for whole seedlings or mature leaves and even down to $5 \mathrm{~s}$ in the most favorable case (wounding stress, data not shown). Thus, values of $\mathrm{Ca}^{2+}$ wave propagation speed as fast as $0.5-0.6 \mathrm{~mm} / \mathrm{s}$ can be resolved (Figure 9, Tables 1, 2).

We consider that G5A reporter opens exciting perspectives for the study of cell-to-cell communication in plants. The physiological meaning of $\mathrm{Ca}^{2+}$ waves observed within vascular tissues (but not solely there) is one of the interesting aspects which could be investigated. Velocity values observed for these $\mathrm{Ca}^{2+}$ signals are of the same order of magnitude than those of "fast" electrical signals (i.e., "action potentials") reported to travel leaf tissues in Arabidopsis (Favre et al., 2011). This substantiates the hypothesis of an interplay between $\mathrm{Ca}^{2+}$ and electrical signaling (Król et al., 2011). Recently, glutamate receptor-like putative $\mathrm{Ca}^{2+}$ channels were reported to play a role in leaf to leaf signaling after wounding (Mousavi et al., 2013), together with electrical signals. In this context, combining G5A-based imaging of $\mathrm{Ca}^{2+}$ with electrophysiological recording of electrical signals might be a powerful method to decipher the molecular basis of electrical signaling in plants upon different types of stress, including wounding.

In conclusion, G5A allows to image free $\mathrm{Ca}^{2+}$ elevation in intact plant leaves, making this probe a promising addition in the toolbox of plant cell physiology. $\mathrm{Ca}^{2+}$ imaging in intact plant leaves with widely affordable imaging equipment has the potential to boost the investigation of $\mathrm{Ca}^{2+}$ signaling in plants.

\section{ACKNOWLEDGMENTS}

We thank Dr. T. Nakagawa (Nagoya, Shimane University, Japan) for the pGWB502 $\Omega$ plasmid, Prof. M. Knight (Durham University, UK) for the Aeq line (pMAQ2, Col-0 ecotype), the 

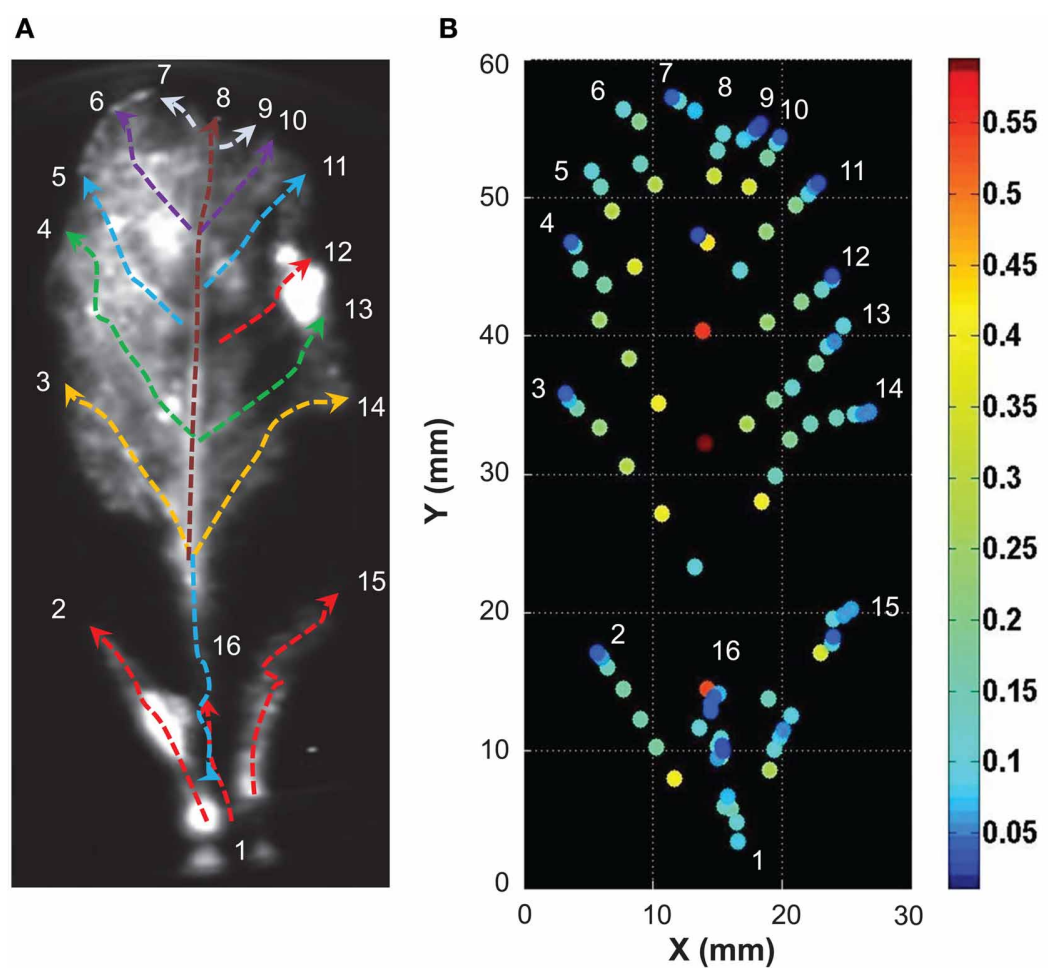

FIGURE 9 | Analysis of the propagation of calcium elevation in detached leaves induced by high salt exposure. (A) $\mathrm{Ca}^{2+}$ responses on each vein were analyzed in ImageJ. Velocities $(\mathrm{mm} / \mathrm{s})$ of $\mathrm{Ca}^{2+}$ signals were determined along paths represented by dashed arrows (details of $\mathrm{Ca}^{2+}$ signal velocity, duration and latency are presented on Table 2; colors of dashed arrows refer to the latency values so that $\mathrm{Ca}^{2+}$ waves that started at similar times are in the same color). (B) Propagation speeds along the main leaf vein are indicated for selected points (same space scale as in $\mathbf{A}$ ). False color scale is in $\mathrm{mm} / \mathrm{s}$.

Table 2 | $\mathrm{Ca}^{2+}$ wave properties in detached leaves upon high salt exposure.

\begin{tabular}{|c|c|c|c|c|c|c|}
\hline $\begin{array}{l}\text { Number of } \\
\mathrm{Ca}^{2+} \text { responses }\end{array}$ & $\begin{array}{l}\text { Total length } \\
\text { (mm) }\end{array}$ & $\begin{array}{c}\text { Velocity mean } \\
\text { (mm/s) }\end{array}$ & $\begin{array}{l}\text { Velocity minimum } \\
\qquad(\mathrm{mm} / \mathrm{s})\end{array}$ & $\begin{array}{l}\text { Velocity maximum } \\
\qquad(\mathrm{mm} / \mathrm{s})\end{array}$ & $\begin{array}{l}\text { Duration* } \\
\text { (s) }\end{array}$ & $\begin{array}{l}\text { Latency* } \\
\text { (s) }\end{array}$ \\
\hline 1 & 8.62 & $0.12 \pm 0.02$ & 0.06 & 0.20 & 75 & 0 \\
\hline 2 & 17.01 & $0.16 \pm 0.04$ & 0.03 & 0.41 & 105 & 30 \\
\hline 3 & 17.34 & $0.19 \pm 0.05$ & 0.04 & 0.39 & 90 & 150 \\
\hline 4 & 20.33 & $0.19 \pm 0.04$ & 0.03 & 0.40 & 105 & 165 \\
\hline 5 & 13.18 & $0.22 \pm 0.06$ & 0.09 & 0.36 & 60 & 195 \\
\hline 6 & 10.63 & $0.18 \pm 0.04$ & 0.10 & 0.28 & 60 & 195 \\
\hline 7 & 2.88 & $0.06 \pm 0.02$ & 0.04 & 0.10 & 45 & 255 \\
\hline 8 & 32.90 & $0.31 \pm 0.08$ & 0.09 & 0.60 & 105 & 150 \\
\hline 9 & 2.78 & $0.04 \pm 0.01$ & 0.01 & 0.07 & 75 & 240 \\
\hline 10 & 9.94 & $0.13 \pm 0.06$ & 0.02 & 0.35 & 75 & 195 \\
\hline 11 & 10.21 & $0.11 \pm 0.03$ & 0.03 & 0.23 & 90 & 195 \\
\hline 12 & 9.77 & $0.13 \pm 0.04$ & 0.02 & 0.24 & 75 & 195 \\
\hline 13 & 14.41 & $0.14 \pm 0.03$ & 0.04 & 0.27 & 105 & 165 \\
\hline 14 & 17.59 & $0.15 \pm 0.04$ & 0.04 & 0.40 & 120 & 150 \\
\hline 15 & 20.04 & $0.11 \pm 0.03$ & 0.03 & 0.35 & 180 & 0 \\
\hline 16 & 20.25 & $0.10 \pm 0.04$ & 0.02 & 0.54 & 195 & 150 \\
\hline
\end{tabular}

*Time resolution is limited by the time acquisition (15s).

late Prof. Philippe Brûlet (CNRS, Gif-sur-Yvette, France) who kindly provided us with the $G 5 A$ construct that we used to build the G5A line. This work was supported by a joint CNRSINRA fellowship to Elsa Ronzier, by the Agropolis Fondation
(Grant 0803-022), and by the European Commission's FP7 (Grant IRG 268393). We are grateful to Drs. Cliona Hann and Siobhán Staunton for their helpful comments on the manuscript. 


\section{SUPPLEMENTARY MATERIAL}

The Supplementary Material for this article can be found online at: http://www.frontiersin.org/journal/10.3389/fpls.2014.00043/ abstract

Supplementary video S1 | Light emission from 4 week-old G5A-expressing leaves upon a high salt stimulus applied to roots of the plant presented in

Figures 5, 6. The left part (A) shows the bright field view of the plant (scale bar is $2 \mathrm{~cm}$ ). Video in the right part (B) is made of frames, each corresponding to photons collected over a $30 \mathrm{~s}$ time lapse, displayed at a rate of three frames per second (video rate is $\times 90$ ). At time zero of the video, the plant has been adapted to dark for 20 min and no $\mathrm{Ca}^{2+}$ signals were detected (data not shown). Application of $200 \mathrm{mM} \mathrm{NaCl}$ to roots at $t=5 \mathrm{~min}\left(3.33 \mathrm{~s}\right.$, video time) induced propagation of $\mathrm{Ca}^{2+}$ elevation over long distances from roots to leaves over $77 \mathrm{~min}$. $\mathrm{NaCl}$-induced $\mathrm{Ca}^{2+}$ waves were different in expanded leaves and in young ones. Propagation of strong $\mathrm{Ca}^{2+}$ elevations to fully expanded leaves can be visualized just after the $\mathrm{NaCl}$ stress and is followed by slow $\mathrm{Ca}^{2+}$ variations in leaves over $77 \mathrm{~min}$. Small young leaves emit strong and transient $\mathrm{Ca}^{2+}$ elevation only 3.5-4.5 min after the $\mathrm{NaCl}$ stress (5.66-6.66 s, video time).

\section{Supplementary video S2 | Second example of light emission from 4} week-old G5A-expressing leaves upon a high salt stimulus applied to roots of the same plant. The left part $(\mathbf{A})$ shows the bright field view of this plant (scale bar is $2 \mathrm{~cm}$ ). Video in the right part $(\mathbf{B})$ is made of frames, each corresponding to photons collected over a $30 \mathrm{~s}$ time lapse, displayed at a rate of three frames per second (video rate is $\times 90$ ). At time zero of the video, the plant has been adapted to dark for 20 min and no $\mathrm{Ca}^{2+}$ signals were detected (data not shown). Application of $200 \mathrm{mM} \mathrm{NaCl}$ to roots at $t=5 \mathrm{~min}\left(3.33 \mathrm{~s}\right.$, video time) induced propagation of a $\mathrm{Ca}^{2+}$ elevation over long distances from roots to leaves over $150 \mathrm{~min}$. As in video $\mathrm{S} 1, \mathrm{NaCl}$-induced $\mathrm{Ca}^{2+}$ waves were different in expanded leaves and in young ones. In this other plant, however, propagation rates and kinetics of $\mathrm{Ca}^{2+}$ changes were different from those in the plant featured in video $\mathrm{S} 1$, exemplifying the complex nature of $\mathrm{Ca}^{2+}$ responses in intact plants.

Supplementary video S3 | Light emission by a leaf detached from a G5A plant upon a high-salt stimulus applied to the petiole. The left part (A) shows the bright field view of the leaf (scale bar is $1 \mathrm{~cm}$ ). Video in the right part $(\mathbf{B})$ is made of frames, each corresponding to photons collected over a $15 \mathrm{~s}$ time lapse, displayed at a rate of six frames per second (video rate is $\times 90$ ). At time zero no light is detected. Application of $200 \mathrm{mM} \mathrm{NaCl}$ to petiole at $t=1 \mathrm{~min}\left(0.66 \mathrm{~s}\right.$, video time) induced $\mathrm{Ca}^{2+}$ waves from petiole to leaf tips over $7 \mathrm{~min}$.

\section{Supplementary video S4 | Second example of light emission from a} detached G5A-expressing leaf upon a high salt stimulus applied to the petiole. The left part (A) shows the bright field view of the leaf (scale bar is $1 \mathrm{~cm}$ ). Video in the right part $(\mathbf{B})$ is made of frames, each corresponding to photons collected over a $15 \mathrm{~s}$ time lapse, displayed at a rate of six frames per second (video rate is $\times 90$ ). At time zero no light is detected. Application of $200 \mathrm{mM} \mathrm{NaCl}$ to petiole at $t=1 \mathrm{~min}(0.66 \mathrm{~s}$, video time) induced $\mathrm{Ca}^{2+}$ waves from the petiole to leaf tips over $17 \mathrm{~min}$. In this leaf from another plant, however, propagation rates and kinetics of $\mathrm{Ca}^{2+}$ changes were different from those in the leaf featured in video S3, exemplifying the complex nature of $\mathrm{Ca}^{2+}$ responses in excised leaves.

\section{REFERENCES}

Allen, G. J., Kwak, J. M., Chu, S. P., Llopis, J., Tsien, R. Y., Harper, J. F., et al. (1999). Cameleon calcium indicator reports cytoplasmic calcium dynamics in Arabidopsis guard cells. Plant J. 19, 735-747. doi: 10.1046/j.1365313x.1999.00574.x

Alonso, M. T., and Garcia-Sancho, J. (2011). Nuclear $\mathrm{Ca}^{2+}$ signalling. Cell Calcium 49, 280-289. doi: 10.1016/j.ceca.2010.11.004

Baubet, V., Le Mouellic, H., Campbell, A. K., Lucas-Meunier, E., Fossier, P., and Brulet, P. (2000). Chimeric green fluorescent protein-aequorin as bioluminescent $\mathrm{Ca}^{2+}$ reporters at the single-cell level. Proc. Natl. Acad. Sci. U.S.A. 97, 7260-7265. doi: 10.1073/pnas.97.13.7260

Benikhlef, L., L'Haridon, F., Abou-Mansour, E., Serrano, M., Binda, M., Costa, A., et al. (2013). Perception of soft mechanical stress in Arabidopsis leaves activates disease resistance. BMC Plant Biol. 13:133. doi: 10.1186/1471-2229-13-133

Bonza, M. C., Loro, G., Behera, S., Wong, A., Kudla, J., and Costa, A. (2013). Analyses of $\mathrm{Ca}^{2+}$ accumulation and dynamics in the endoplasmic reticulum of Arabidopsis root cells using a genetically encoded Cameleon sensor. Plant Physiol. 163, 1230-1241. doi: 10.1104/pp.113.226050

Brini, M. (2008). Calcium-sensitive photoproteins. Methods 46, 160-166. doi: 10.1016/j.ymeth.2008.09.011

Cassidy, P. J., and Radda, G. K. (2005). Molecular imaging perspectives. J. R. Soc. Interface 2, 133-144. doi: 10.1098/rsif.2005.0040

Chiesa, A., Rapizzi, E., Tosello, V., Pinton, P., De Virgilio, M., Fogarty, K. E., et al. (2001). Recombinant aequorin and green fluorescent protein as valuable tools in the study of cell signalling. Biochem. J. 355, 1-12. doi: 10.1042/02646021:3550001

Clough, S. J., and Bent, A. F. (1998). Floral dip: a simplified method for Agrobacterium-mediated transformation of Arabidopsis thaliana. Plant J. 16, 735-743. doi: 10.1046/j.1365-313x.1998.00343.x

Dodd, A. N., Jakobsen, M. K., Baker, A. J., Telzerow, A., Hou, S. W., Laplaze, L., et al. (2006). Time of day modulates low-temperature $\mathrm{Ca}^{2+}$ signals in Arabidopsis. Plant J. 48, 962-973. doi: 10.1111/j.1365-313X.2006.02933.x

Fasano, J. M., Swanson, S. J., Blancaflor, E. B., Dowd, P. E., Kao, T. H., and Gilroy, S. (2001). Changes in root cap $\mathrm{pH}$ are required for the gravity response of the Arabidopsis root. Plant Cell 13, 907-921. doi: 10.2307/3871348

Favre, P., Greppin, H., and Degli Agosti, R. (2011). Accession-dependent action potentials in Arabidopsis. J. Plant Physiol. 168, 653-660. doi: 10.1016/j.jplph.2010.09.014

Fricker, M. D., Plieth, C., Knight, H., Blancaflor, E., Knight, M. R., White, N. S., et al. (1999). "Chapter forty-two - fluorescence and luminescence techniques to probe ion activities in living plant cells," in Fluorescent and Luminescent Probes for Biological Activity, 2nd Edn, ed W. T. Mason (London: Academic Press), 569-596.

Gjetting, K. S., Ytting, C. K., Schulz, A., and Fuglsang, A. T. (2012). Live imaging of intra- and extracellular $\mathrm{pH}$ in plants using $\mathrm{pHusion}$, a novel genetically encoded biosensor. J. Exp. Bot. 63, 3207-3218. doi: 10.1093/jxb/ers040

Gorokhovatsky, A. Y., Marchenkov, V. V., Rudenko, N. V., Ivashina, T. V., Ksenzenko, V. N., Burkhardt, N., et al. (2004). Fusion of Aequorea victoria GFP and aequorin provides their $\mathrm{Ca}^{2+}$-induced interaction that results in red shift of GFP absorption and efficient bioluminescence energy transfer. Biochem. Biophys. Res. Commun. 320, 703-711. doi: 10.1016/j.bbrc.2004.06.014

Iwano, M., Ngo, Q. A., Entani, T., Shiba, H., Nagai, T., Miyawaki, A., et al. (2012). Cytoplasmic $\mathrm{Ca}^{2+}$ changes dynamically during the interaction of the pollen tube with synergid cells. Development 139, 4202-4209. doi: 10.1242/dev.081208

Johnson, C. H., Knight, M. R., Kondo, T., Masson, P., Sedbrook, J., Haley, A., et al. (1995). Circadian oscillations of cytosolic and chloroplastic free calcium in plants. Science 269, 1863-1865. doi: 10.1126/science.7569925

Knight, M. R., Campbell, A. K., Smith, S. M., and Trewavas, A. J. (1991). Transgenic plant aequorin reports the effects of touch and cold-shock and elicitors on cytoplasmic calcium. Nature 352, 524-526. doi: 10.1038/352524a0

Krebs, M., Held, K., Binder, A., Hashimoto, K., Den Herder, G., Parniske, M., et al. (2012). FRET-based genetically encoded sensors allow high-resolution live cell imaging of $\mathrm{Ca}^{2+}$ dynamics. Plant J. 69, 181-192. doi: 10.1111/j.1365313X.2011.04780.x

Król, E., Płachno, B. J., Adamec, L., Stolarz, M., Dziubińska, H., and Trębacz, K. (2011). Quite a few reasons for calling carnivores 'the most wonderful plants in the world'. Ann. Bot. 109, 47-64. doi: 10.1093/aob/mcr249 
Marti, M. C., Stancombe, M. A., and Webb, A. A. (2013). Cell- and stimulus type-specific intracellular free $\mathrm{Ca}^{2+}$ signals in Arabidopsis. Plant Physiol. 163, 625-634. doi: 10.1104/pp.113.222901

Martin, J. R., Rogers, K. L., Chagneau, C., and Brulet, P. (2007). In vivo bioluminescence imaging of $\mathrm{Ca}^{2+}$ signalling in the brain of Drosophila. PLoS ONE 2:e275. doi: 10.1371/journal.pone.0000275

Mithofer, A., and Mazars, C. (2002). Aequorin-based measurements of intracellular $\mathrm{Ca}^{2+}$-signatures in plant cells. Biol. Proced. Online 4, 105-118. doi: $10.1251 /$ bpo40

Miwa, H., Sun, J., Oldroyd, G. E., and Downie, J. A. (2006). Analysis of calcium spiking using a cameleon calcium sensor reveals that nodulation gene expression is regulated by calcium spike number and the developmental status of the cell. Plant J. 48, 883-894. doi: 10.1111/j.1365-313X.2006.02926.x

Monshausen, G. B., Messerli, M. A., and Gilroy, S. (2008). Imaging of the Yellow Cameleon 3.6 indicator reveals that elevations in cytosolic $\mathrm{Ca}^{2+}$ follow oscillating increases in growth in root hairs of Arabidopsis. Plant Physiol. 147, 1690-1698. doi: 10.1104/pp.108.123638

Monshausen, G. B., Miller, N. D., Murphy, A. S., and Gilroy, S. (2011). Dynamics of auxin-dependent $\mathrm{Ca}^{2+}$ and $\mathrm{pH}$ signaling in root growth revealed by integrating high-resolution imaging with automated computer vision-based analysis. Plant J. 65, 309-318. doi: 10.1111/j.1365-313X.2010.04423.x

Mousavi, S. A., Chauvin, A., Pascaud, F., Kellenberger, S., and Farmer, E. E. (2013). GLUTAMATE RECEPTOR-LIKE genes mediate leaf-to-leaf wound signalling. Nature 500, 422-426. doi: 10.1038/nature12478

Nakagawa, T., Suzuki, T., Murata, S., Nakamura, S., Hino, T., Maeo, K., et al. (2007). Improved Gateway binary vectors: high-performance vectors for creation of fusion constructs in transgenic analysis of plants. Biosci. Biotechnol. Biochem. 71, 2095-2100. doi: 10.1271/bbb.70216

Naumann, E. A., Kampff, A. R., Prober, D. A., Schier, A. F., and Engert, F. (2010). Monitoring neural activity with bioluminescence during natural behavior. Nat. Neurosci. 13, 513-520. doi: 10.1038/nn.2518

Perez Koldenkova, V., and Nagai, T. (2013). Genetically encoded $\mathrm{Ca}^{2+}$ indicators: Properties and evaluation. Biochim. Biophys. Acta. 1833, 1787-1797. doi: 10.1016/j.bbamcr.2013.01.011

Rivadossi, A., Zucchelli, G., Garlaschi, F. M., and Jennings, R. C. (2004). Light absorption by the chlorophyll a-b complexes of photosystem II in a leaf with special reference to LHCII. Photochem. Photobiol. 80, 492-498. doi: 10.1562/0031-8655(2004)080<0492:LABTCA >2.0.CO;2

Rogers, K. L., Martin, J. R., Renaud, O., Karplus, E., Nicola, M. A., Nguyen, M., et al. (2008). Electron-multiplying charge-coupled detector-based bioluminescence recording of single-cell $\mathrm{Ca}^{2+}$. J. Biomed. Opt. 13, 031211. doi: $10.1117 / 1.2937236$

Rogers, K. L., Stinnakre, J., Agulhon, C., Jublot, D., Shorte, S. L., Kremer, E. J., et al. (2005). Visualization of local $\mathrm{Ca}^{2+}$ dynamics with genetically encoded bioluminescent reporters. Eur. J. Neurosci. 21, 597-610. doi: 10.1111/j.14609568.2005.03871.x

Sai, J., and Johnson, C. H. (2002). Dark-stimulated calcium ion fluxes in the chloroplast stroma and cytosol. Plant Cell 14, 1279-1291. doi: 10.1105/tpc.000653

Schneider, C. A., Rasband, W. S., and Eliceiri, K. W. (2012). NIH Image to ImageJ: 25 years of image analysis. Nat. Methods 9, 671-675. doi: 10.1038/nmeth.2089

Steinhorst, L., and Kudla, J. (2013). Calcium and reactive oxygen species rule the waves of signaling. Plant Physiol. 163, 471-485. doi: 10.1104/pp.113.222950

Taylor, K. L., Brackenridge, A. E., Vivier, M. A., and Oberholster, A. (2006). High-performance liquid chromatography profiling of the major carotenoids in Arabidopsis thaliana leaf tissue. J. Chromatogr. A 1121, 83-91. doi: 10.1016/j.chroma.2006.04.033

Verrillo, F., Occhipinti, A., Kanchiswamy, C. N., and Maffei, M. E. (2014). Quantitative analysis of herbivore-induced cytosolic calcium by using a Cameleon (YC 3.6) calcium sensor in Arabidopsis thaliana. J. Plant Physiol. 171, 136-139. doi: 10.1016/j.jplph.2013.09.020

Ward, W. W., and Cormier, M. J. (1976). In vitro energy transfer in Renilla bioluminescence. J. Phys. Chem. 80, 2289-2291. doi: 10.1021/j100561a030

Webb, S. E., Rogers, K. L., Karplus, E., and Miller, A. L. (2010). The use of aequorins to record and visualize $\mathrm{Ca}^{2+}$ dynamics: from subcellular microdomains to whole organisms. Methods Cell Biol. 99, 263-300. doi: 10.1016/B978-0-12374841-6.00010-4

Zhu, X., Feng, Y., Liang, G., Liu, N., and Zhu, J. K. (2013). Aequorin-based luminescence imaging reveals stimulus- and tissue-specific $\mathrm{Ca} 2+$ dynamics in Arabidopsis plants. Mol. Plant. 6, 444-455. doi: 10.1093/mp/sst013

Conflict of Interest Statement: The authors declare that the research was conducted in the absence of any commercial or financial relationships that could be construed as a potential conflict of interest.

Received: 12 December 2013; accepted: 29 January 2014; published online: 18 February 2014.

Citation: Xiong TC, Ronzier E, Sanchez F, Corratgé-Faillie C, Mazars C and Thibaud $J-B$ (2014) Imaging long distance propagating calcium signals in intact plant leaves with the BRET-based GFP-aequorin reporter. Front. Plant Sci. 5:43. doi: 10.3389/fpls. 2014.00043

This article was submitted to Plant Cell Biology, a section of the journal Frontiers in Plant Science.

Copyright (C) 2014 Xiong, Ronzier, Sanchez, Corratgé-Faillie, Mazars and Thibaud. This is an open-access article distributed under the terms of the Creative Commons Attribution License (CC BY). The use, distribution or reproduction in other forums is permitted, provided the original author(s) or licensor are credited and that the original publication in this journal is cited, in accordance with accepted academic practice. No use, distribution or reproduction is permitted which does not comply with these terms. 